\title{
The Monash University Museum of Computing History: Ten Years On
}

\author{
A. Barbara Ainsworth, Chris Avram, and Judithe Sheard \\ Faculty of Information Technology \\ Monash University \\ \{Barbara.Ainsworth, Chris.Avram, Judy. Sheard\} \\ einfotech.monash.edu.au
}

\begin{abstract}
The Monash Museum of Computing History was established at Monash University, Melbourne, Australia in 2001. This university museum has a growing collection of early computer equipment and a permanent exhibition tracing the development of computing technology within an Australian context and particularly related to computing at Monash University. The Museum has been evolving since its inception with greater definition of its collection policy, defined collection management and its role as a repository for computing history and the dissemination of its research. This paper gives an overview of the origins of the Museum, current activities and future directions.
\end{abstract}

Keywords: history of computing, computing museum.

\section{Introduction}

The Monash Museum of Computing History $(\mathrm{MMoCH})$ is located at the Caulfield campus of Monash University, Melbourne, Australia. The Museum is an initiative of the Faculty of Information Technology and combines a physical exhibition, a collection of original material and research activities. It was started in 2001 with a brief to collect original computing material around the University and develop an exhibition. The role of the Museum has expanded with continued collecting and research but we are currently exploring new methods of presenting this information to both students and other interested users through public programs. It is appropriate to provide a review of the first ten years surveying the origins of the Museum, its collection and research activities, exhibition program and public programs as well as discussing the future directions now in planning. This paper gives an overview of the origins of the Museum, current activities and future directions.

\subsection{Background of Museum}

The concept of a museum at Monash University was inspired by a speech by Max Burnet to staff from the Faculty of Information Technology in 2001. Max Burnet is well known in Australian computing history research as a major collector of early computer material and he is an authority on the development of computing in Australia. His speech highlighted the rapid change in computer technology and the lack of 
preservation of early material as most institutions replace old technology on a regular basis. Older equipment was generally seen as a nuisance, something occupying valuable space and disposable. Dr Judithe Sheard, Senior Lecturer in the Caulfield School of Information Technology, heard Max's speech and felt the significance of older equipment used at Monash University should not be lost. She approached the Faculty and gained permission to develop a museum that would preserve this early technology and produce a physical display.

There have been computing activities at Monash University and other institutions that have amalgamated with the University since the early $1960 \mathrm{~s}^{1}$. The University created the Faculty of Computing and Information Technology, now called the Faculty of Information Technology, in $1990^{2}$. Remnants of past installations and equipment were spread across different departments and locations. The amalgamation of the separate teaching institutions led to the existence of a number of historical computing installations and equipment being used at the different schools and departments. Gradually a large variety of objects, documents and photographs were assembled and a display was established in October 2001 at the Caulfield campus. This was the first stage of the Museum and the Museum has since continued to collect material and improve its physical display as well as develop its museological practices.

Dr Sheard continues her involvement as Director and Sarah Rood, who was working for the Faculty, was seconded to work on the Museum relocation during 2004 and 2005. Together they produced the current major permanent exhibition. An advisory committee was established to give both computing and museum advice. In late 2006 Barbara Ainsworth took up the position of part-time Curator and started formally cataloguing the collection with supportive research. Chris Avram has been an Honorary Consultant since the beginning of the project. Several other academic staff continue to provide research and practical assistance when required. Max Burnet has maintained his connection with the Museum, providing both advice and loan material. Museum personnel have continued to develop both the Museum's practices and exhibitions as well as produce supportive activities and publications.

The Museum has received ongoing funding for collection management and exhibition development. Professor Ron Weber, Dean of the Faculty, has been generous in his continuing interest in this project.

\subsection{Purpose of the Museum}

In its original inception, the Museum was established to collect and preserve superseded computing material around Monash University and produce a small didactic exhibition. Museum staff then developed a number of policies to clarify the role of the Museum beyond its initial aims and give an explicit set of objectives as well as a Collection Policy. This set of objectives is necessary to define the Museum's purpose and help shape the direction of future developments and ongoing museum practices. It

${ }^{1}$ Monash University started at the Clayton campus with later amalgamations adding several different campus locations. For a brief history see the Interactive pictorial timeline of Monash University [1].

2 The Faculty of Information Technology represents the current culmination of the gradual development of computing studies at Monash University. Rood gives a summary of these events in her Introduction [2]. 
is a small museum with limited resources and this makes it necessary to have a clear set of objectives. The role of the Museum has been defined with a mission statement to collect and preserve original computing items associated with Monash University and research their provenance, to undertake research on the development of the Faculty and collect biographical material relating to people involved with the Faculty. The Museum also collects supportive material for reference on the history of computing in Australia. It is a primary function of the Museum to make the collection and research material accessible for educational and research purposes. This material is made available to the academic community, students and the general public through exhibitions and lectures. Researchers can also access original material not on display. The museum provides access to research material through publications and the website. The Museum policies are available on the Museum website [3].

The definition of the Museum's role provides a framework for understanding the different areas of activity in the Museum and our current view of the future direction of the Museum. The Museum's primary function is to collect original material and information and present this material in an accessible form to the academic and general community. The different areas of the Museum's work are seen as interactive, using original material and research to provide resources and material to be presented in virtual or physical environments. Currently information is presented through exhibition text, handouts or educational sheets, as well as published material and the website research. The Museum has been developing different aspects of this model.

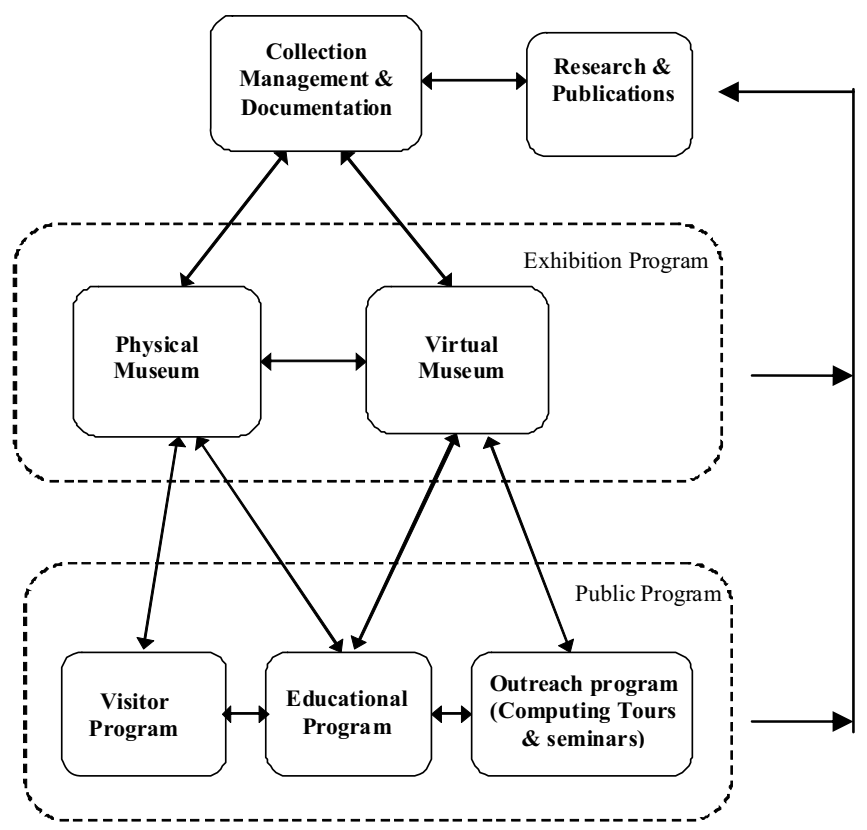

Fig. 1. The Museum Model 


\section{Collection}

A primary aim of the Museum is to acquire original artifacts associated with the development of Monash University's use of computer technology for both administrative and teaching purposes. The collection has a wide variety of calculating and computing material that reflects the changing technology used by staff and students over the last forty years.

The University was given its charter to start a new institution in 1958 and the acquisition of computing equipment was given an early priority. After long consideration by a special committee, the University ordered a Ferranti Sirius computer from the English company Ferranti Ltd. It was shipped from England and installed by November 1962. Further investigations revealed that were actually four different Sirius computers at the current campuses of Monash at different times over the 1960s. These four computers were located at different sites in 1962 with two Sirius computers at the Melbourne Computer Centre operated by Ferranti Ltd, one at the Clayton campus of Monash University, and one at a commercial research operation run by ICIANZ, now called ORICA, at Ascot Vale. Through loan, donation and sales all four were located at some point at Monash University. One of these machines managed to survive in storage at the Clayton campus and was transferred to the Museum at the Caulfield campus in 2005. It is now a major exhibit in the permanent display. The MMoCH Ferranti Sirius is displayed in a dedicated showcase and includes the 1000 word CPU and an additional 3000 word memory cabinet along with a suite of I/O (input/output) equipment. Further information on the history of the Ferranti Sirius at Monash University is available from an article by Barbara Ainsworth [4] accessed from the Museum website [3].

The Ferranti Sirius was one of the larger items found around the campuses of Monash for the Collection but other interesting items appeared out of storage. An early calculating machine called The Millionaire had been housed in the Maths Department and was donated to the Museum. The Millionaire was based on a design created by the Frenchman Leon Bollee and patented in Germany in the early 1890s by Otto Steiger. The design was further improved by Hans W.Egli in Switzerland, and was manufactured in Zurich from 1893. All machines were given an individual identifying number. They are built mainly of cast iron and brass and weigh about 33 kilograms. Although once commonly used for mechanical multiplication in business, there are now about only 22 examples remaining in Australia. The machine in the $\mathrm{MMoCH}$ collection is numbered 913 and was probably produced during the period 1898-1900. For further reading on the Millionaire see John Wolff's Web Museum [5].

Others items in the collection reflect the teaching role of the university. This includes an example of the computer system which was used in the MONECS project. In the late 1970 s a school could only afford one computer, so how could 30 children run a program with only one card punch machine and a one hour lesson period? The answer was provided by an ingenious system developed by Monash University. The class would write their programs on mark sense cards, and each deck could be run on the MONECS computer in a few seconds. That way, every student had a chance to run a program in a one hour lesson. The MONECS (Monash Educational Computer System) scheme was a project administered by the Monash Computing Centre and developed by Professor Cliff Bellamy and his associates as a teaching tool for 
Monash students as well as off-campus students to develop computer programming skills. The system ran on a PDP-11 which could be a stand-alone system accepting input from cards. This computer was mobile and could be sent out to schools and TAFEs and other tertiary institutions. There were over 30 outside users in the early 1980s. Monash was running 12 PDP-11 and Spectrum systems in $1984^{3}$.Students without access to a computer on-site could use mark-sensed cards which were marked by the students at their institution and the cards were then sent to Monash Computer Centre to be run at quiet times, and then returned to the outside school. The MONECS is part of an autobiographical display in the Museum on the work of Professor Cliff Bellamy.

Recently the Museum was able to co-ordinate the return of a computer used in the MONADS project [6]. The MONADS Project was initiated by Professor Leslie Keedy in 1976 at Monash University; it was an umbrella project for related research activities concerned with design of computer systems. This computer design and development project was undertaken in the Department of Computer Science, Clayton campus into the mid-1980s by Professors Leslie Keedy, John Rosenberg and David Abramson. Students and staff continued this research at Monash University until 1985 and then at other institutions. The MONADS I and II computers consisted of a series of circuit boards which were installed into a Hewlett-Packard HP-2100A minicomputer. Professor Chris Wallace and Robert Hagan had already modified the HP2100A adding a virtual memory system. The MONADS projects used this virtual memory system as a base for further developments. Professor Keedy went to Darmstadt in Germany and continued the project. One of the "MONADS PCs" has recently been returned from the University of Ulm in Germany to the Museum. The machine was designed by Professor David Abramson and Professor John Rosenberg in the mid 1980's while they were academics in the Department of Computer Science at Monash University.

The Museum collection has been catalogued and now numbers over 700 items. New material is regularly offered to the Museum. Currently we are creating a database with these records. John Sheard, an Access database developer, has volunteered his expertise and created an Access database specifically for this purpose. The material has also been classified with an in-house classification system. A large number of items have been placed on permanent exhibition with the remainder in storage. Material in storage is accessible upon request to the Director and is used for lecturing to visiting groups. The Museum does occasionally lend material for teaching purposes.

\section{Stages of Exhibition Work}

\subsection{First Exhibition}

The Museum opened its first exhibition in October 2001 with a display of computing material set in a chronological format. The display was entitled 'A Digital Evolution',

\footnotetext{
${ }^{3}$ References on this project are held in the Monash University Archives. Papers include internal memo by Cliff Bellamy 9 May 1984, also printout of users in1984 on file in MU Archives MON 935 1999/6 MONECS 1981-82. See article Monecs Monash Educational Computer System by Cliff Bellamy 13 July 1984 in MU Archives MON 935 1999/6 MONECS 198182.
} 
and was an exhibition of computing history. The display was located at the Caulfield campus. This display included a mixture of computing equipment used on campus and some loan items ranging from slide rules and calculators to card readers and early Apple personal computers. Max Burnet placed his example of the computer PDP 9 on display. It was originally installed at La Trobe University, Melbourne in 1967. A team of interested staff, students and outside advisors contributed to the initial development under the direction of Dr Sheard. Professor David Abramson, then Head of School, was very supportive of the project and organized departmental funding. Max Burnet provided both his knowledge and loan items for the first display. He developed the initial display and wrote the text for the display signage. The display labels were then designed by an art and design student. The technical people in the School helped move the equipment.

A temporary display, entitled "Ways and Means of Computing", was also held at the Monash Science Centre, Clayton campus, Monash University in 2002. The display was curated by Dr Sheard with the exhibition content and research developed by Dr Selby Markham. While the display featured original computing material, it also included a number of interactive exhibits to demonstrate concepts behind computing, including a Mechanical Binary Counting Device and model slide rules.

\subsection{Permanent Exhibition, Caulfield Campus, Monash University}

The current permanent physical display is in the foyer of Building B, Caulfield campus and was officially opened on 11 May 2005. The University received generous funding and support from a number of sources including Multimedia Victoria, $\mathrm{Mu}-$ seum Victoria, Australian Computer Society, IKEA, The Age, Floorbotics, Microsoft and Holden Ltd.

The exhibition has four main areas of display. The introductory area features the concept of calculating by external means. The early calculating equipment highlights the problems of mechanical computation. There have been different solutions to this problem and the display features a number of mechanical counting devices, electromechanical calculators and the hand-held electronic calculators of the 1970s. There is also a variety of slide rules ranging from the common academic slide rules to specialized devices. Once an essential tool for all mathematicians and engineers, these slide rules are completely unknown to our student visitors. These forms of calculating are a precursor to the use of stored memory computers.

The major display area is devoted to the development of computers with examples used since the late 1950s through to the modern era of ubiquitous and mobile computing. The range of computers shows the commercial sized operations, including the PDP-9 (on loan from Max Burnet) and a console from the computer model IBM $360 / 30$, to a range of early home computers from BBC, Commodore, Acorn and Atari. The Apple Macintosh range is also represented with an APPLE II and an APPLE LISA on display. The computers are displayed in a chronological sequence but a major feature is a pictorial background to the computers. The large range of images represents contemporaneous events to the technological developments. This places the computers within a sociological framework of current events and influences in Australia. 
A dedicated showcase features the Ferranti Sirius which was installed at Monash University in 1962. The basic Sirius CPU had 1000 words of store but could be expanded with extra memory units with a 3000 word store. The Sirius on display has the CPU with one extra memory cabinet. The Sirius uses acoustic delay line memory. All input was through punch tape. The showcase also includes a Ferranti paper tape reader, Ferranti Westrex paper tape punch, a Creed teletype and a Creed paper tape reader set on a table. The display is supported by a short b/w film which was produced for the British Railways by Mr.S.E. Fargher in 1963. Fargher's film explains the process of using the Sirius to solve a problem in simple language. The MMoCH transferred the 4000 word machine to the Caulfield campus in 2005. A special committee was formed to help the museum prepare the machine for display and it was relocated to Building B foyer. The committee members were volunteers including Peter Thorne, Judy Hughes, Jurij Semkin and John Spencer. They cleaned the various parts of the Sirius. These volunteers had experience with restoring CSIRAC for the Melbourne Museum. The real-time clock was restored to working order by Chris Avram and Bruce Gilligan.

The fourth part of the display features biographies of people associated with computing at Monash University through management, teaching or research. The first biographies examined the work of Professor Chris Wallace, Professor Cliff Bellamy and Dr Andrew Prentice. Professors Wallace and Bellamy made significant contributions to the development of computing at Monash University. Cliff Bellamy had a long association with the Monash Computer Centre in his role as Director from 1964 and then became the first dean of the current Faculty of Information Technology. Professor Chris Wallace was Foundation Professor of the Department of Information Science which was established at Clayton campus in the Faculty of Science in 1968. More recently in April 2008 the display was updated to include material on the work of Professor John Rosenberg and Professor David Abramson. These biographies feature equipment and publications as well as photographic and text displays.

\subsection{Multimedia Project with Arts Faculty}

Teaching the history of computing is widely accepted as an important way of helping IT students to better understand their field. This was acknowledged in 1991 with the inclusion of history modules in the ACM/IEEE curriculum for computer science [7]. While the Monash Museum of Computing History is a valuable resource for this purpose, MMoCH staff are collaborating with staff from the Faculty of Arts on a Virtual Museum Project (VMP) to further develop the $\mathrm{MMoCH}$ resource by bringing to life the physical exhibits with computer-generated animation. Geoff Berry from the History Department developed a concept to connect different technology over a timeframe. Daniel Simmonds and Dr Tom Chandler from the Multimedia Department, Berwick campus, provided the technical multimedia component of the project.

The first stage of this project has been completed with the production of a short video which covers a period from the mid 60s to the mid 70s. The development of computer technology is illustrated through a story of space exploration. The 'virtual tour' takes in the Ferranti Sirius, the PDP-9, and the hand-held HP-65 calculator. The animated narrative places the technology in the context of current events, helping 
students understand the influences of computers on society and the factors that influenced the development of computer technology. The video can be explored from a number of different aspects relevant to a broad range of computer science courses. Further description of this resource is available elsewhere [8].

\section{Publications and Research Activities}

\subsection{History Publications}

The Faculty of Information Technology, Monash University commissioned a history of the Faculty after the idea was discussed at the launch of the $2001 \mathrm{MMoCH}$ display. Professor John Rosenberg, Dean of the Faculty from 1997-2003, agreed that the period of time leading up to the formation of the Faculty coincided with significant changes in the approach to teaching information technology and the Faculty should support a history publication. A steering committee was formed to guide the project. Sarah Rood, as well as being Curator for the $\mathrm{MMoCH}$, was given the contract to write the history. The book follows the development of computing at Monash University, starting with the Monash Computer Centre and the beginnings of the teaching school in the late 1960s to the establishment of a separate faculty in 1990. The author interviewed a large number of people, including former students and staff, involved with computing at Monash over the past thirty years. The book From Ferranti to Faculty was published in 2008 [9].

In 2008 the Museum was represented in inroads, SIGCSE Bulletin with a two part article about the Museum. This was a great opportunity to raise the profile of the Museum and highlight some of the interesting parts of the collection to a wide audience $[10,11]$.

\subsection{Research}

Internal research has been focused on material within the collection. This has been particularly important for establishing the provenance of the Ferranti Sirius computer in the collection. It came from the Clayton campus into the collection in 2001, but we were aware that Monash University had donated another Sirius to Melbourne $\mathrm{Mu}$ seum in 1975. Director Judithe Sheard had also received a number of communications from older staff members with their recollections about the Ferranti Sirius at Monash University. These recollections proved to be quite confusing and it became apparent that they referred to several different installations. After examining historical resources, including Monash University Archives and ORICA Library and Archives, we now understand that there were four different Sirius computers in Melbourne during the early 1960s and all four were located at Monash University at different points in time. We have also been fortunate to have received assistance with technical and historical information from members of the British Computer Conservation Society. This collaboration has led to the inclusion of an article on the Sirius at Monash University in the magazine RESURRECTION, The Bulletin of the Computer Conservation Society [12]. 


\section{Public Program}

The MMoCH has developed a number of public activities to raise the profile of the Museum and introduce aspects of the collection and display to a larger audience.

\subsection{Museum Website}

The Museum has developed a website to provide information on the Museum and its operational matters. The site also allows access to some of the current research projects being undertaken at the Museum. A number of leaflets on specific topics are also posted. These include a brief history of computing at Monash University, the Ferranti Sirius computer in the collection and notes on early calculators. Another aim of the site is to provide resources for further study and indicates other locations for information on computing history. The website can be found at http://www.infotech.monash.edu.au/about/projects/museum/

\subsection{Seminar with Gordon Bell - Bits and Bytes}

In May 2008 the MMoCH hosted a seminar with guest Gordon Bell giving an address on his view of current uses for the recording of personal information as well as a seminar on the Computer History Museum, California. Gordon Bell spoke about his latest work in developing the MyLifeBits project which is an experiment in using multimedia to record every aspect of his daily life. The MyLifeBits project seeks to record these in a personal transaction processing database [13].

Gordon Bell has a long career in the computing industry starting with 23 years (1960-1983) at Digital Equipment Corporation. He has been involved with a number of advisory committees, including the Sector Advisor Committee of the ICT Division, CSIRO, encouraging the development of new computer technology. Currently Gordon is a principal researcher in the Microsoft Research Silicon Valley Research Group. In 1979 Gordon Bell and Gwen Bell were co-founders of the Computer Museum, Boston, Massachusetts. This museum developed in Boston but the collection was later transferred to California and became the Computer History Museum in Mountain View, California. Gordon's background gives him a unique perspective on computer technology and the role of computer museums.

This seminar was a joint project between the Monash University's MMoCH, eResearch and the Centre for Community and Organisational Informatics (COSI). The seminar drew an interested group from the academic, museum and professional IT areas. The success of this event has encouraged the $\mathrm{MMoCH}$ to organize more events in the future.

\subsection{Computer History Tours}

In 2008 Associate Professor Graham Farr approached the $\mathrm{MMoCH}$ to collaborate on a new initiative to create a history of computing tour using the Melbourne tramway system to connect different museum exhibitions and sites with a general theme of computer history. The tour groups usually number between 30-40 people with Graham Farr, Judithe Sheard, Chris Avram and Barbara Ainsworth providing a narrative at 
different sites. The tour can also be undertaken as a self-guided individual activity using tour notes from the website. A list of suggested sites and more extensive notes can be accessed through the Computing in Melbourne: A Historical Tour website [14].

These tours commence at the $\mathrm{MMoCH}$ exhibition at Caulfield campus and then the tour usually follows the tram route from Caulfield, into St Kilda Road, then the Royal Botanical Gardens, into the City precinct. The tour then continues with a visit to the computer exhibition at Melbourne Museum featuring CSIRAC, the only remaining $1^{\text {st }}$ generation stored program computer $[15,16]$. The tour then concludes with a visit to Melbourne University to discuss the first Internet connections in Australia. The different sites can be varied for the tour. The sites do not necessarily have original computing equipment but are used as an introduction to a related computing history topic. Usually these tours, which are free, are run on a weekend but are also available by special arrangement. This has been an interesting exercise for both the guides and participants. Different people attend the tours including current academic staff, postgraduate and undergraduate students as well as many retired IT professionals. The conversations stimulated by the tour notes and information have introduced many new topics and sources of information for further research.

\section{Future Directions}

The Monash Museum of Computing History future development is directed towards creating a virtual museum presentation. This on-line educational environment will be a learning space where students and other interested users can explore the history of computing with a special focus on Australian computing history and Monash University's part in this history. This facility will provide another component in the $\mathrm{Mu}$ seum's different physical and virtual presentations and link its research program and collection with on-line visitors who can participate in different forms of access for varying purposes. It will be a virtual space on the Internet that provides a multimedia portal into the history of the development of computers including both the technological advances and the social implications of this technological change within an Australian context. The project will use a range of resources to give the visitor a variety of information sources including in-depth text-based research information or interactive participation using different media including three-D imaging and original moving or still images. The portal will also give access to view the physical collections and displays at Monash University. The site will provide different levels of access that address the specific needs and internet literacy of the visitor. It is anticipated that the project will be used as a resource for different levels of academic users, remote visitors and general interest users and respond to their differing needs. Students would also have educational resources and teaching material available to support their studies. Another feature of the Museum will be an interactive component where visitors can contribute their own knowledge and experiences to our reference base.

The basic level of access would be through a timeline which gives linkage points to topics mentioned in the timeline text. The timeline provides all visitors with a summary of the narrative of the overall topic, the beginnings of stored memory computers within the context of the history of calculating and the use of numbers with special reference to Australian developments. The timeline is then the starting point for a 
visitor to explore the main points further. By clicking on a topic, the visitor is then offered a range of sub-topics presented in different formats. They can read text or activate presentations of original footage or still images. The preliminary multimedia project (described earlier) has been investigating the development of imaging early technology and activating the images in a realtime situation to recreate the technology in a contemporaneous context. For specialized visitors, an access point is provided for collection searches on the $\mathrm{MMoCH}$ physical collection. This would show the provenance and physical attributes of these objects as well as images. A visitor can also have a virtual tour of the current physical display at the museum.

This project is still in the planning stages but staff have had preliminary meetings with academic advisers from the History Department and the IT Faculty, Monash University. The Museum hopes to provide a portal on the history of computing which exploits the skills of different faculties to interpret the Museum's physical collection and research. The Internet will allow the Museum to reach a wider audience and provide a resource for different levels of students as well as the general user.

\section{Conclusion}

The Monash Museum of Computing History is a relatively new university museum but, through the use of modern media, it aims to provide information and resources to a wide community of users. The physical collection gives staff and students a base for research in a number of areas including technological developments and historical interpretation of the impact of these developments. Future plans will expand the outreach of the Museum from the immediate university environs to a much larger audience through the Internet.

\section{References}

1. Our History, achievements and milestones: 1990 - Caulfield and Peninsula campuses established (1990),

http: //www. monash. edu.au/timeline/1990-caulfieldpeninsula.html (accessed: February 25, 2010)

2. Rood, S.: From Ferranti to Faculty: Information Technology at Monash University, pp. ix-x. 1960 to 1990 Monash University ePress, Melbourne (2008)

3. Monash Museum of Computing History, http://www.infotech.monash.edu.au/about/projects/museum (accessed: February 25, 2010)

4. Ainsworth, A.B.: The Ferranti Sirius computer at Monash University (2008), http://www. infotech.monash. edu.au/about/projects/museum/pape rs/first-computer-at-monash-university-v4.pdf (accessed: February 25, 2010)

5. John Wolff's Web Museum, http://home.vicnet.net.au/ wolff/calculators/Egli/Egli.htm (accessed: February 25, 2010)

6. The Monads Project, http://monads-security.org/ (accessed: February 25, 2010) 
7. Lee, J.A.N.: History in the computer science curriculum. ACM SIGCSE Bulletin 28(2), 15-20 (1996)

8. Berry, G., Sheard, J., Quartly, M.: A Virtual Museum of Computing History: an educational resource bringing the relationship between people and computers to life. Paper Submitted to Australasian Computing Education Conference (2011)

9. Rood, S.: From Ferranti to Faculty: Information Technology at Monash University. 1960 to 1990 Monash University ePress, Melbourne (2008)

10. Ainsworth, A.B., Sheard, J., Avram, C.: Monash Museum of Computing History Part I. SIGSCE Bulletin Inroads 40(2), 31-34 (2008)

11. Ainsworth, A.B., Sheard, J., Avram, C.: Monash Museum of Computing History Part II. SIGSCE Bulletin Inroads 40(4), 31-34 (2008)

12. Ainsworth, B.: The Ferranti Sirius at Monash University, RESURRECTION. The Bulletin of the Computer Conservation Society (44) (August 2008), http: / / www.cs.manchester.ac.uk/CCS/res/res 44 .htm (accessed: February 25,2010$)$

13. Gemmell, J., Bell, G., Lueder, R.: MyLifeBits: A personal Database for Everything. Communications of the ACM 49(1), 44-50 (2006)

14. Computing in Melbourne: A Historical Tour, http: / /www.csse.monash.edu.au/ gfarr/tour/

15. CSIRAC: Australia's first computer, Museum of Victoria, http: / /www. museum.vic.gov.au/csirac/ (accessed: February 25, 2010)

16. McCann, D., Thorne, P.: The Last of the First. CSIRAC: Australia's First Computer. University of Melbourne (2000) 